\title{
Tudo como dantes? Reflexos da pandemia de Covid-19 sobre graduandos da Educação a Distância
}

\author{
Daniel Santos Braga ${ }^{1}$ \\ Isabella Adriane Martins Pereira ${ }^{2}$
}

\section{RESUMO}

Este estudo investigou impactos da pandemia da Covid-19 em 2020 sobre os processos de ensino-aprendizagem de estudantes de nível superior da Educação a Distância. Foi realizado survey on-line para aferir em que medida a adoção de estratégias de enfrentamento da pandemia, em especial o isolamento social, afetou a realidade dos graduandos. Compuseram a amostra 385 estudantes das cinco regiões do país. Foi possível traçar um perfil socioeconômico dos estudantes e verificar como a pandemia afetou seus contextos familiares e acadêmicos. O isolamento social se refletiu no aumento de tarefas domésticas e do compartilhamento de dispositivos, na perda da qualidade de internet e na diminuição do tempo de estudo. Quanto à aprendizagem e rendimento, a pandemia afetou os estudantes da EaD de maneira desigual.

Palavras-chave: Educação Superior. Educação a Distância. Repercussões da Covid-19.

\footnotetext{
${ }^{1}$ danielsantosbraga@gmail.com - Centro Universitário Newton Paiva, Universidade do Estado de Minas Gerais

${ }^{2}$ isabellaadriane@outlook.com - Universidade Federal de Minas Gerais
} 


\section{Everything as before? Reflexes of the Covid-19 pandemic on distance education undergraduates}

\section{ABSTRACT}

This study investigated the impacts of the Covid-19 pandemic (2020) on the teaching-learning processes of higher education students in Distance Education. An on-line survey was conducted to assess how the adoption of strategies to cope with the pandemic, especially social isolation, affected the reality of the undergraduates. The sample consisted of 385 students from the five regions of the country. It was possible to draw a socioeconomic profile of the students and verify how the pandemic affected their family and academic contexts. Social isolation was reflected in increased household chores, sharing of devices, loss of internet quality and decreased study time. However, regarding learning and achievements, the pandemic affected the students unequally.

Keywords: Higher education. Distance education. Repercussions of the Covid-19. 
O ano de 2020 foi marcado pela declaração de emergência de saúde pública de importância internacional pela Organização Mundial da Saúde (OMS) devido ao surto de COVID-19, cujo agente etiológico é o novo coronavírus (SARS-CoV-2). Em todo o mundo, milhões de pessoas foram infectadas e um grande número delas veio a óbito em decorrência de complicações ocasionadas pela doença (WHO, 2020a).

Os poderes públicos e as autoridades de saúde dos países adotaram diferentes estratégias de enfrentamento à disseminação da doença, com maiores ou menores taxas de eficácia e eficiência. Uma das estratégias não farmacêuticas referendada pela OMS e com maior difusão foi o isolamento social quando constatada transmissão comunitária do vírus (WHO, 2020b). O objetivo do isolamento era reduzir a velocidade da transmissão e não deixar que serviços de saúde, particularmente leitos hospitalares de Unidades de Tratamento Intensivo e respiradores mecânicos, entrassem em colapso pelo esgotamento de suas capacidades (OPAS, 2020).

No Brasil, por não constar dentre as atividades consideradas essenciais (BRASIL, 2020) e por seu potencial de aglomeração de pessoas, os serviços educacionais tanto de nível básico quanto superior foram interrompidos, com exceção daqueles que ocorriam na modalidade de Educação a Distância (EaD). Em 17 de março de 2020, pela Portaria n 343', o Ministério da Educação se manifestou sobre a substituição das aulas presenciais por aulas em meios digitais enquanto durasse a situação de pandemia, no que se convencionou chamar de Ensino Remoto Emergencial (ERE) (HODGES et al., 2020).

Diversos estudos têm se dedicado a analisar as repercussões da pandemia na educação, tanto no mundo e suas regiões (UNESCO, 2020; GARRIDO; 2020) como no Brasil (PALÚ; SCHÜTZ; MAYER, 2020; CURY, 2020; ARRUDA, 2020). Pesquisas sobre os impactos do ERE nas diferentes etapas da Educação Básica (RIBEIRO; CLÍMACO, 2020); na inclusão de alunos com necessidades educacionais especiais (ABREU, 2020); na saúde mental de estudantes (DUTRA; CARVALHO; SARAIVA, 2020; MAIA; DIAS, 2020); na organização de atividades da Educação Superior (PEREIRA et al., 2020); no trabalho docente (OLIVEIRA, 2021), dentre outras temáticas têm lançado luz a respeito de como a pandemia da COVID-19 tem afetado os processos educativos, com especial destaque para os múltiplos desdobramentos da adoção de modelos não presenciais na realidade de estudantes.

Por outro lado, ainda são escassos estudos que tratam de repercussões da pandemia sobre processos de ensino-aprendizagem que se efetivam predominantemente a distância, por meio da modalidade EaD. Em levantamento preliminar - não exaustivo e não sistemático - até a data da publicação deste artigo não foi identificado nenhum trabalho que tratasse dessa questão nas bases da Biblioteca Eletrônica Científica On-line (SciELO) e Google Scholar. Da mesma forma, não foi encontrada nenhuma pesquisa em revistas temáticas sobre Educação a Distância como, por exemplo, na Revista Brasileira de Aprendizagem Aberta e a Distância (RBAAD) da Associação Brasileira de Educação a Distância (ABED); na Revista de Educação a Distância (EmRede) da Associação Universidades em Rede; e na Revista Científica em Educação a Distância (EaD em Foco)ii do Centro de Ciências e Educação Superior a Distância do Estado do Rio de Janeiro. 
Uma possível hipótese para essa lacuna é a compreensão de que, como esses estudantes já estavam acostumados a um tipo não presencial de organização do processo de ensinoaprendizagem, a emergência da pandemia não teria afetado - ou teria afetado pouco - esses estudantes. Afinal, é razoável supor que alunos matriculados e cursando a EaD já estivessem familiarizados com as dinâmicas características dessa modalidade: encontros síncronos, atividades assíncronas; equipamentos, plataformas virtuais, recursos de aprendizagem etc. Assim, as dificuldades de adaptação de alunos e professores do ensino regular para o ERE, já reportados por diferentes trabalhos (DIAS; PINTO, 2020; DI BENEDITTO, 2020; OLIVEIRA; MOTA; BRAGA, 2020), não seriam determinantes para estudantes da EaD.

Há indícios, no entanto, para se pensar que, a despeito da suposta maior familiaridade com práticas não presenciais de ensino-aprendizagem, outros elementos poderiam impactar estudantes da EaD no contexto da pandemia de COVID-19 em 2020. Os dados do Censo da Educação Superior do Instituto Nacional de Estudos e Pesquisas Educacionais Anísio Teixeira (INEP) de 2018 e os questionários contextuais do Exame Nacional de Desempenho de Estudantes (ENADE) revelam, por exemplo, que a maior parte dos estudantes de tal modalidade no Brasil vive em grandes cidades, são casados e com filhos, além de trabalharem para pagar por seus próprios estudos (INEP, 2017-19; INEP, 2018). Assim, medidas de isolamento social teriam potencial para afetar a realidade desses estudantes.

Diante desse cenário, esta pesquisa tem como objetivo investigar possíveis reflexos da pandemia sobre estudantes de graduação matriculados em cursos EaD no Brasil. A pergunta a ser respondida é: apesar de já estarem matriculados em cursos não presenciais, a emergência da pandemia da COVID-19 e as políticas de isolamento social impactaram os processos de ensinoaprendizagem desses estudantes? A hipótese em questão é que o perfil dos estudantes EaD da Educação Superior no país sugere que estão sujeitos a terem suas rotinas de estudo afetadas social, econômica e academicamente por repercussões suscitadas pelo contexto.

\section{GRADUAÇÃO EM EAD NO BRASIL: ASPECTOS HISTÓRICOS, LEGAIS E EDUCACIONAIS}

A EaD, mais próxima do que se conhece hoje em dia com o uso da internet e aplicação da didática por meio de vídeos, áudios, atividades síncronas e assíncronas, surgiu entre os anos de 1980 e 1990 no Brasil com a difusão de novas Tecnologias de Informação e Comunicação (TICs) no país. A nova realidade tecnológica trouxe consigo diferentes possibilidades de dinâmicas entre educação e o uso intensivo de dispositivos digitais conectados com a superação de espaço-tempo e novas formas de comunicação refletindo diretamente na produção de conhecimentos e nas relações sociais (ALONSO; SILVA, 2018).

A metodologia de ensino que ganhou força nas últimas décadas surgiu, dentre outros objetivos, com a potencialidade de democratização de acesso ao Ensino Superior, levando em consideração a possibilidade de expansão e de alcance de áreas não privilegiadas pelas instituições superiores presenciais, notadamente as universidades públicas, tornando as limitações físicas e estruturais menos relevantes. 
No que se refere às políticas públicas, a Educação a Distância aparece em termos legais pela primeira vez com a promulgação da Lei n ${ }^{\circ} 9.394$ de 1996:

Art.80: o Poder Público incentivará o desenvolvimento e a veiculação de programas de ensino a distância, em todos os níveis e modalidades de ensino, e de educação continuada (BRASIL, 1996).

Sua regulamentação só ocorreu pelo decreto nº 2.494 de 10 de fevereiro de 1998:

Art. $1^{\text {o: }}$ Educação a distância é uma forma de ensino que possibilita a autoaprendizagem, com a mediação de recursos didáticos sistematicamente organizados, apresentados em diferentes suportes de informação, utilizados isoladamente ou combinados, e veiculados pelos diversos meios de comunicação (BRASIL, 1998).

Conforme observado por Arruda e Arruda (2015), a lei trazia em seu texto interpretações confusas e controversas sobre a EaD, ao destacar a descentralização do papel docente no processo educativo e a ideia de possibilidade do autoaprendizado.

Em 19 de dezembro de 2005, um novo decreto, $n^{\circ}$ 5.622, entra em vigor (BRASIL, 2005) A nova legislação passou a caracterizar melhor as definições a respeito da EaD, com artigos que evidenciam questões referentes à organização e ao financiamento, além de abranger a possibilidade de oferta em EaD a todos os níveis inclusive a pós-graduação. O decreto já trazia em suas ideias as grandes mudanças das tecnologias de informação, principalmente no que se diz respeito à interatividade (ARRUDA; ARRUDA, 2015).

O decreto atualmente vigente é o $n^{\circ} 9.057$ de 25 de maio de 2017 (BRASIL, 2017). Entre as principais mudanças, destaca-se a não obrigatoriedade de as instituições de Ensino Superior ofertar cursos presenciais para assim estarem habilitadas a disporem de cursos a distância. Além disso, as universidades públicas passaram a estar automaticamente vinculadas para exercerem a modalidade EaD. $O$ decreto pode ser considerado um dos responsáveis pelo crescimento exponencial da Educação a Distância nos últimos anos em instituições públicas, seguindo ao que já estava consolidado nas instituições privadas.

As discussões educacionais em relação a EaD abordam seus aspectos positivos e negativos. Em relação as suas possibilidades, as pesquisas apontam que a modalidade favorece a expansão do ensino para localidades onde não existem instituições presenciais. Sua forma didática possibilita que pessoas com limitações em relação à rotina de trabalho, por exemplo, tenham acesso facilitado ao Ensino Superior. Os custos mais baixos em relação à infraestrutura, com a possibilidade de contratação menor de professores, resultam em um custo operacional reduzido, o que, segundo Arruda e Arruda (2015), destaca ainda a característica potencializadora da EaD em relação à ampliação do Ensino Superior.

Também é preciso encarar com cautela a modalidade. Alguns autores destacam os limites da EaD. Alonso e Silva (2018) avaliam que a baixa inserção de alunos em relação à pesquisa e extensão, observando o tangenciamento em relação aos objetivos de ensino dos conteúdos curriculares são fatores problemáticos presentes em diversas realidades de instituições pelo país. Outro aspecto importante ressaltado pelo estudo da ABED (2017) está relacionado à grande taxa 
de evasão e à qualidade de oferta de cursos referente aos desafios organizacionais. Ao analisar algumas das principais políticas públicas concernentes à $\mathrm{EaD}$ - que de certa forma dão brechas para tais problemas - pode-se perceber que decorrente a suas inserções em um contexto recente no cenário brasileiro, necessitam de melhores estruturações no tocante às concepções de aprendizagem, financiamento, expansão e da própria pesquisa.

Dada a normatização da EaD no ordenamento jurídico educacional brasileiro e sua expansão nas últimas décadas, notadamente no Ensino Superior, se justifica uma pesquisa que visa avaliar se - e como - a pandemia da COVID-19 no ano de 2020 impactou à realidade de estudantes matriculados nessa modalidade no país.

\subsection{Materiais e Métodos}

Para o cumprimento do objetivo da pesquisa foi realizado survey on-line - ComputerAssisted Web Interviewing - a fim de se aferir em que medida a adoção de estratégias de enfrentamento da pandemia, em especial o isolamento social, afetou a realidade de estudantes matriculados em cursos de graduação na modalidade EaDiii. A pesquisa por questionário objetiva reunir uma grande quantidade de informações - tanto factuais quanto subjetivas - de um número significativo de indivíduos de forma a permitir inferências com significância estatística sobre as características de uma população (PARIZOT, 2008).

O questionário era composto por três blocos de questões: o primeiro dedicado a aspectos relativos à dados pessoais, demográficos e socioeconômicos; o segundo sobre aspectos contextuais do respondente - seu cotidiano no cenário da pandemia; e o terceiro com perguntas sobre aspectos acadêmicos e educacionais - Quadro 1. O objetivo do primeiro bloco foi estabelecer o perfil dos estudantes. 0 segundo bloco intentou avaliar como a emergência da pandemia alterou a rotina doméstica e familiar dos estudantes. Por fim, o último grupo de questões objetivou captar as percepções dos estudantes EaD sobre como a pandemia repercutiu em sua realidade educacional. As questões foram aferidas em pré-teste realizado com 17 estudantes, todos da região metropolitana de Belo Horizonte.

\section{Quadro 1: Blocos de perguntas do questionário}

\begin{tabular}{|c|c|c|}
\hline Aspectos pessoais & Aspectos contextuais & Aspectos acadêmicos \\
\hline Área de estudos & \multirow{2}{*}{$\begin{array}{l}\text { Dificuldades pessoais no contexto } \\
\text { da pandemia }\end{array}$} & \multirow{3}{*}{$\begin{array}{l}\text { Interferências das atividades } \\
\text { domésticas/familiares nas } \\
\text { atividades acadêmicas }\end{array}$} \\
\hline Tipo de curso superior & & \\
\hline Unidade da Federação & \multirow{2}{*}{$\begin{array}{l}\text { Tipos de atividades domésticas } \\
\text { realizadas }\end{array}$} & \\
\hline Tamanho do município & & \multirow{4}{*}{$\begin{array}{l}\text { Percepção da interferência do } \\
\text { compartilhamento de aparatos } \\
\text { nas relações de ensino- } \\
\text { aprendizagem }\end{array}$} \\
\hline Estado civil & \multirow{2}{*}{$\begin{array}{l}\text { Isolamento de pessoas do mesmo } \\
\text { convívio familiar }\end{array}$} & \\
\hline Raça/cor & & \\
\hline Identificação de gênero & \multirow{2}{*}{$\begin{array}{l}\text { Aparato digital para acesso aulas e } \\
\text { atividades on-line }\end{array}$} & \\
\hline Idade & & \multirow{3}{*}{$\begin{array}{l}\text { Horas semanais dedicadas aos } \\
\text { estudos antes e durante a } \\
\text { pandemia }\end{array}$} \\
\hline Local de moradia & \multirow{2}{*}{$\begin{array}{l}\text { Compartilhamento de aparato } \\
\text { tecnológico utilizado }\end{array}$} & \\
\hline Pessoas na moradia & & \\
\hline Renda familiar & \multirow{3}{*}{$\begin{array}{l}\text { Percepção de qualidade da rede } \\
\text { de internet }\end{array}$} & \multirow{3}{*}{$\begin{array}{l}\text { Percepção sobre rotina de } \\
\text { estudos, rendimento acadêmico }\end{array}$} \\
\hline Situação financeira & & \\
\hline Situação de trabalho & & \\
\hline
\end{tabular}


Se teve financiamento

estudantil

Fonte: Elaborado pelos autores, com base no pré-teste realizado. e saúde mental durante a

pandemia

O método da amostragem foi do tipo estratificada proporcional (PINHEIRO et al., 2012). A amostra calculada considera um nível de confiança de $95 \%$ e erro amostral de 5 pontos. $O$ cálculo foi feito a partir do total de estudantes matriculados no Ensino Superior EaD no país pelos dados do Censo da Educação Superior do INEP (2018) sendo o N considerado para o cálculo amostral de 3.259.785 alunos, ponderado por região do país. A fórmula utilizada foi:

$$
n=\frac{N \times\left(\frac{1}{E_{0}^{2}}\right)}{N+\left(\frac{1}{E_{0}^{2}}\right)}
$$

Onde N é o tamanho da população; E é erro amostral tolerável; $\mathrm{E}_{\mathrm{o}}{ }^{2}$ - inverso do erro ao quadrado - é a primeira aproximação para o tamanho da amostra para o grau de confiança estabelecido. Sendo assim, chegou-se à amostra total para o país de 385 estudantes a responderem o questionário, distribuídos conforme proporção de alunos matriculados em EaD em cada região - Tabela 1. A fim de se ter uma amostra mínima para as regiões com menor número de estudantes - Norte e Nordeste -, foi feita uma ponderação qualitativa (PINHEIRO et al., 2012) para melhor representação dessas regiões no desenho da pesquisa.

Tabela 1: Distribuição da amostra a partir do total de estudantes por região

\begin{tabular}{lllll}
\hline Região & Número de estudantes EaD & $\mathbf{\%}$ & Amostra simples & Amostra qualificada \\
\hline Norte & 15.422 & 0,5 & 2 & 10 \\
\hline Nordeste & 148.483 & 4,6 & 18 & 25 \\
\hline Sudeste & 1.283 .909 & 39,4 & 151 & 145 \\
\hline Sul & 1.447 .522 & 44,4 & 171 & 162 \\
\hline Centro-Oeste & 364.449 & 11,2 & 43 & 43 \\
\hline Total & $\mathbf{3 . 2 5 9 . 7 8 5}$ & $\mathbf{1 0 0 , 0}$ & $\mathbf{3 8 5}$ & $\mathbf{3 8 5}$ \\
\hline
\end{tabular}

Fonte: Elaborada pelos autores, com base na pesquisa realizada em INEP (2018).

Um link para o questionário foi disponibilizado em redes sociais, bem como enviado para listas de e-mails de universidades públicas e privadas que ofertam graduação EaD. O convite ao preenchimento da pesquisa também foi encaminhado para associados da $A B E D$, o que possibilitou seu redirecionamento para coordenadores e professores de cursos e, destes, para estudantes da modalidade.

Após, aproximadamente, dois meses de divulgação - novembro e dezembro de 2020 - o total de respondentes para as cinco regiões do país foi alcançado. Apenas para as regiões Sul e Sudeste o número de respondentes foi maior do que o valor estipulado para a amostra - $191 \mathrm{e}$ 212 respectivamente. Dessa forma, foi feita seleção aleatória para a adequação ao calculado na Tabela 1. No caso da região Sudeste, o estado do Espírito Santo não entrou na randomização por ter tido o menor número relativo de respondentes na região. 


\subsection{Resultados e Discussão}

\subsubsection{Perfil socioeconômico dos estudantes EaD pesquisados}

Com a intenção de melhor entendimento e aprofundamento a respeito da pesquisa, viu-se a necessidade de identificar o perfil dos alunos da modalidade EaD quanto a aspectos como sexo, raça, estado civil, bem como a questões referentes às instituições frequentadas e à renda dos pesquisados. Além da demonstração do perfil dos alunos, foi necessário evidenciar por meio de interpretações sucintas outras questões consideradas relevantes pelos autores para o desenvolvimento da pesquisa.

\section{Figura 1 - Dependência administrativa das Instituições de EaD}

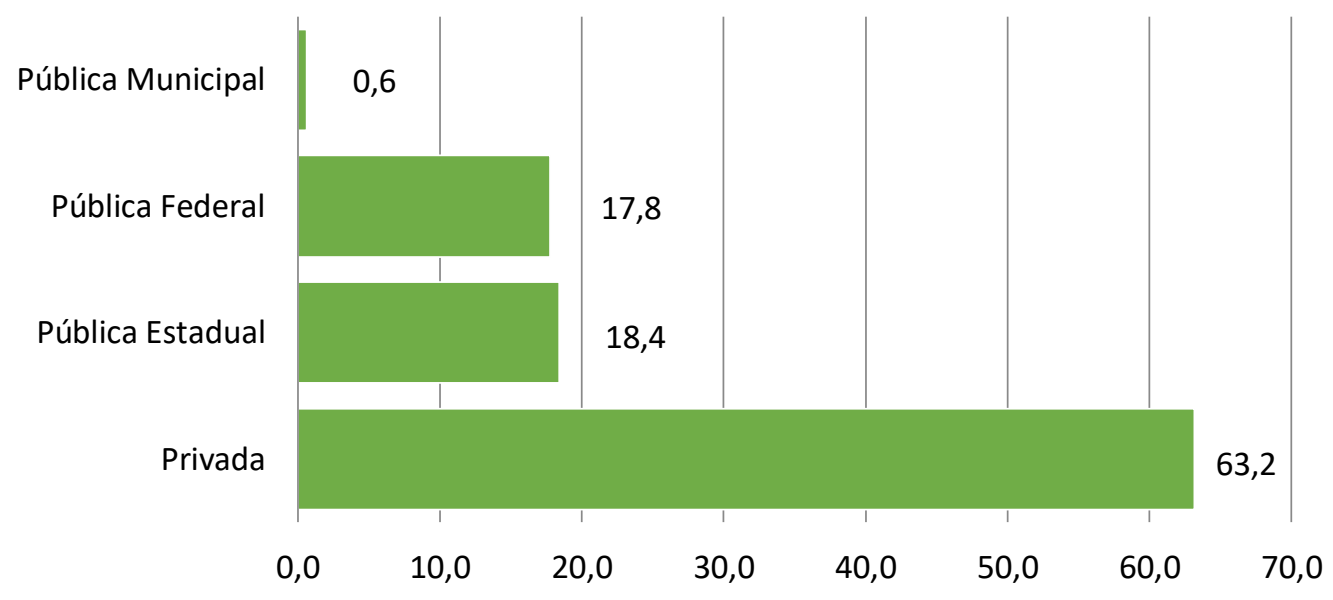

Fonte: Elaborada pelos autores com base na pesquisa realizada.

Ao analisar o gráfico da Figura 1, pode-se perceber que parte significativa dos estudantes $(63,2 \%)$ frequentam instituições de EaD privadas, o que reflete o crescimento exponencial de 145\% na modalidade, entre os anos de 2009 e 2018 (INEP, 2018). O distanciamento existente entre o número de optantes pelas instituições privadas e públicas em geral pode ser justificado pela vigência do decreto de $n^{\circ} 9.057$ de 25 de maio de 2017. A legislação atualmente em vigor pode ser responsável pelo crescimento da modalidade já que traz em seus artigos aspectos favoráveis a estruturação e criação de instituições privadas da modalidade de EaD.

O gráfico da Figura 2 evidencia o porte populacional das cidades em que os pesquisados residem, mostrando que grande parte dos estudantes são moradores das capitas dos Estados. É importante ressaltar que o crescimento da Educação a Distância observado nas médias nacionais e refletido no gráfico, não está diretamente associado à ideia de universalização do Ensino Superior, sendo que $55 \%$ dos participantes residem nas capitais. As cidades de pequeno porte populacional e de área rural têm pouco menos que $20 \%$ de discentes optantes pela EaD respondentes da pesquisa. Assim, o Ensino Superior continua concentrado em capitais mesmo sendo um dos objetivos da EaD a interiorização do nível superior no país. 
Figura 2 - Porte populacional do município de residência dos respondentes

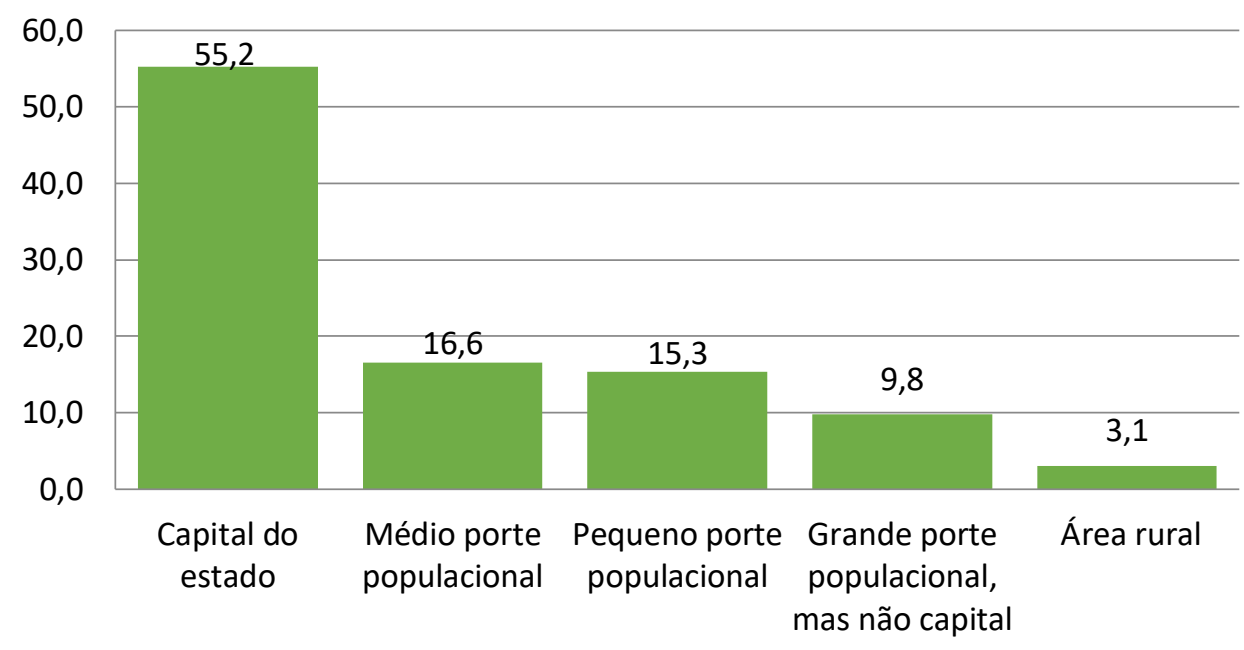

Fonte: Elaborada pelos autores com base na pesquisa realizada.

O gráfico da Figura 3 evidencia que grande parte de estudantes do Ensino Superior da modalidade EaD identificam-se como do sexo feminino. Segundo o Semesp (2020), o público feminino é o maior ocupante do Ensino Superior brasileiro, sendo a ocupação correspondente a $57 \%$ (INEP, 2018) do total de vagas ofertadas. O crescimento ainda maior pode ser observado em relação à EaD, em provável decorrência de adequação do tempo distribuído entre trabalho e atividades domésticas, o que ainda é culturalmente uma sobrecarga sobre o sexo feminino.

\section{Figura 3- Sexo dos respondentes}

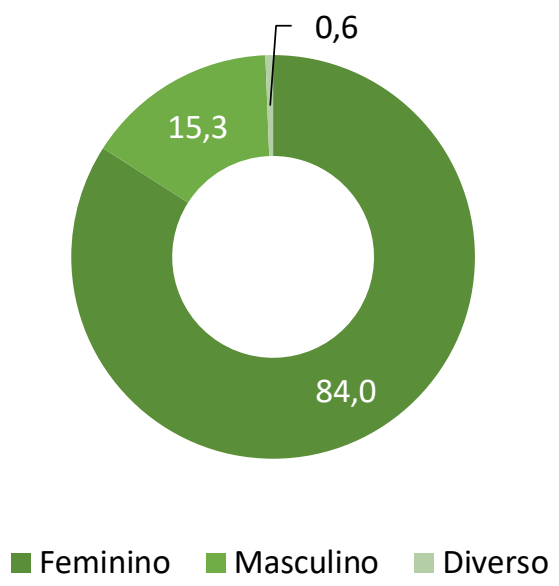

Fonte: Elaborada pelos autores com base na pesquisa realizada.

Os dados do gráfico da Figura 4 apontam que se autodeclaram brancos $42,3 \%$ dos estudantes; pardos, 38,7\%; pretos, 14,1\%; e amarelos apenas 3,1\%. Ao analisar o gráfico tem-se a impressão de que a equiparação de estudantes pretos e pardos com os brancos, em relação ao acesso ao Ensino Superior, foi alcançada por meio de políticas de cotas em conjunto com a Educação a Distância. Ao analisar, porém, os dados do INEP (2018) referentes ao Ensino Superior presencial, é possível perceber que a modalidade ainda tem privado grande parte dos estudantes 
pretos e pardos no que concerne ao seu acesso. Dessa forma, a EaD se torna uma ferramenta para minimizar os impactos das desigualdades presentes no Ensino Superior quanto à raça ou cor.

\section{Figura 4 - Cor/Raça dos respondentes}

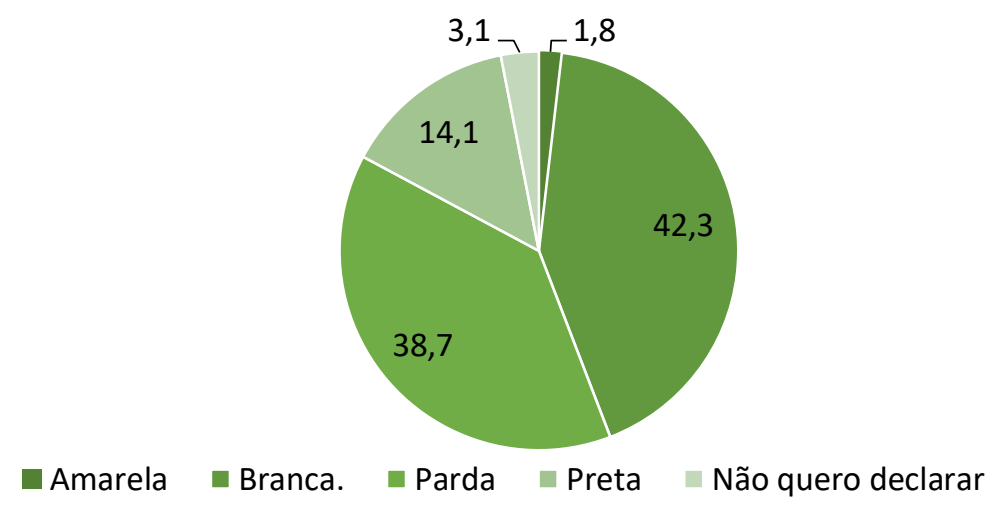

Fonte: Elaborada pelos autores com base na pesquisa realizada.

No tocante à faixa etária dos pesquisados, o respondente mais novo assinalou ter 19 anos e o mais velho, 60. A média das idades foi de 36,6 anos. Isso difere ligeiramente da média das idades em cursos presenciais, em que os estudantes ingressam com média de 24,4 anos (ANDIFES, 2019). Uma possível hipótese é que ao contrário do estudante presencial, que costuma ingressar no Ensino Superior logo após ou pouco tempo depois da formatura da Educação Básica, o estudante EaD, em geral, entra primeiro no mercado de trabalho e constituiu família. Pode-se supor que a opção por um Ensino não presencial se dê como estratégia para conciliar tais necessidades aos estudos.

\section{Figura 5 - Estado civil dos respondentes}

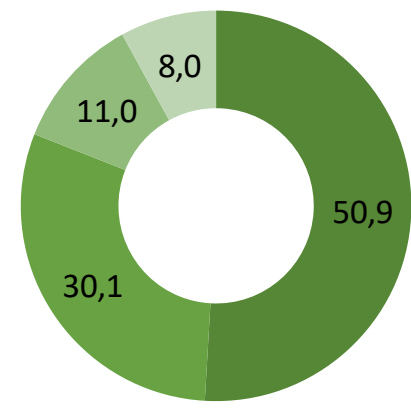

- Casado(a) $\quad$ Solteiro(a) $\quad$ Separado(a) judicialmente/divorciado(a) $\quad$ Outro

Fonte: Elaborada pelos autores com base na pesquisa realizada.

Um fator importante destacado na pesquisa de Semesp (2020) está relacionado à estagnação da taxa de escolarização líquida - 18 a 24 anos -, embora o número de optantes pela modalidade a distância seja significativamente maior que o Ensino Presencial, a estagnação permanece, pois a modalidade não tem atingido o ingresso dos jovens entre 18 e 24 anos ao Ensino Superior. 
A hipótese de que os estudantes da modalidade não presencial primeiramente se estabilizam no mercado de trabalho e constituem família para depois frequentar o Ensino Superior volta a aparecer ao analisarmos o gráfico da Figura 5. Dos colaboradores da pesquisa, os casados representam 50,9\% e $11,0 \%$, os divorciados judicialmente. Da mesma forma, é possível observar no gráfico que uma porcentagem significativa $(69,9 \%)$ dos pesquisados moram com conjugue e/ou filhos.

\section{Figura 6 - Situação de moradia dos respondentes}

Em outros tipos de habitação individual ou coletiva (hotel, hospedaria, pensão ou outro)

Em casa ou apartamento, com outras pessoas (incluindo república)

Em casa ou apartamento, sozinho

Em casa ou apartamento, com pais e/ou parentes

Em casa ou apartamento, com cônjuge e/ou filhos

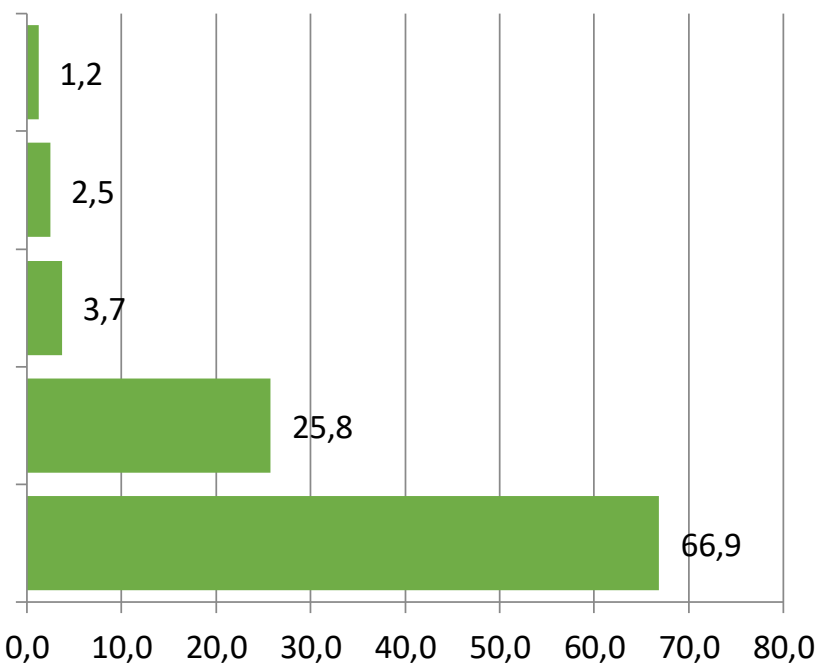

Fonte: Elaborada pelos autores com base na pesquisa realizada.

Em relação à quantidade de residentes que moram com o respondente, foi de 3 pessoas por moradia; e 13,4\% habitam em casas com mais de cinco moradores.

Figura 7 - Renda familiar dos respondentes

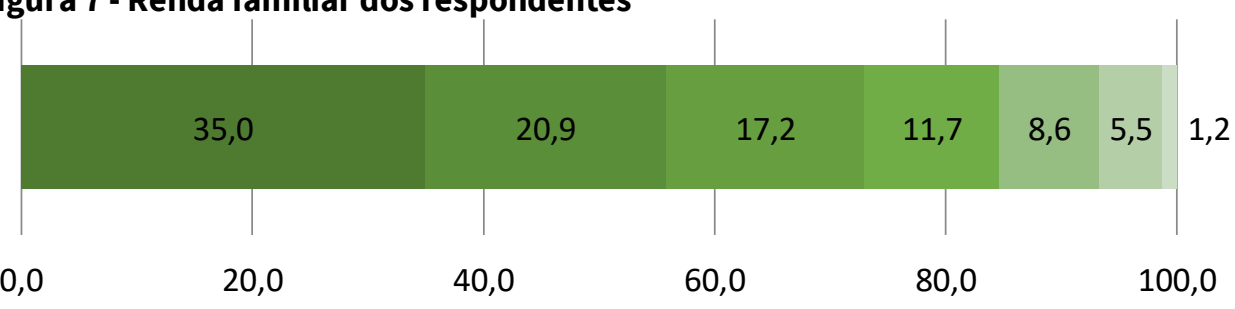

- De 1,5 a 3 salários mínimos ( $R \$ 1.431,01$ a $R \$ 2.862,00)$

De 3 a 4,5 salários mínimos ( $R \$ 2.862,01$ a $\mathrm{R} \$ 4.293,00)$

De 6 a 10 salários mínimos ( $R \$ 5.724,01$ a $\mathrm{R} \$ 9.540,00)$

Até 1,5 salário mínimo (até $R \$ 1.431,00$ )

De 4,5 a 6 salários mínimos (R\$ 4.293,01 a R\$ 5.724,00)

De 10 a 30 salários mínimos (R\$9.540,01 a R\$28.620,00)

Fonte: Elaborada pelos autores com base na pesquisa realizada.

Como observado no gráfico da Figura 7 e, segundo os dados do INEP (2018), a Classe C tem predominado nas instituições de ensino na modalidade a distância. Pode-se perceber ao fazer uma breve análise dos dados que, embora exista variação significativa em relação à renda dos participantes, boa parte deles tem receita superior a três salários-mínimos. Tal afirmação pode 
estar associada ao fato de que boa parte dos adeptos da modalidade não presencial estão inseridos há mais tempo no mercado de trabalho. Também existe a possibilidade de que parte relevante dos pesquisados estejam realizando a segunda graduação. Ainda evidencia-se que uma considerável parcela (40,5\%), além de já estar inserida no mercado de trabalho, contribui com o sustento da família.

\section{Figura 8 - Situação financeira dos respondentes}

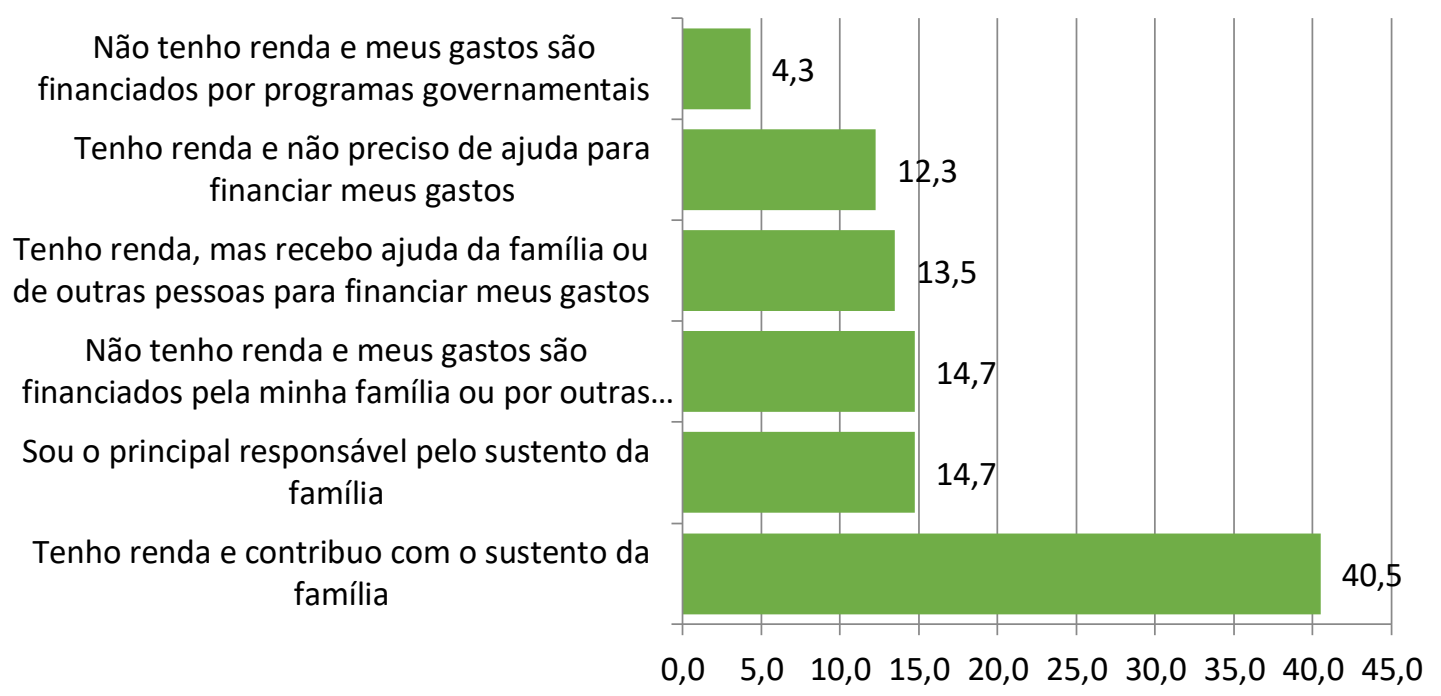

Fonte: Elaborada pelos autores com base na pesquisa realizada.

Logo em seguida, encontra-se o choque de duas realidades distintas que se equiparam pela demonstração no gráfico da Figura 8. Dos pesquisados, 14,7\% são responsáveis pelo sustento da família, assim como 14,7\% não possuem renda e tem os gastos financiados pelos familiares ou por outras pessoas. Tal aproximação, que socialmente se diverge em muitos aspectos, traz-nos a demonstração da variedade a respeito dos adeptos da modalidade não presencial, que engloba alunos recém- formados no Ensino Médio; estudantes que conciliam trabalho formal, trabalho doméstico e a permanência no Ensino Superior; optantes pela segunda graduação através da EaD; pós-graduandos; pessoas que não tiveram oportunidades de inserção quando mais novas no ensino superior, entre outros.

O gráfico da Figura 9 demonstra a carga horária dos estudantes que se submeteram à pesquisa. Percebe-se que a maioria realiza atividade remunerada, sendo que $47,2 \%$ trabalham 40 horas semanais ou mais. Tal resultado pode estar relacionado ao fato de que a modalidade não presencial se torna essencial para associar o trabalho à possibilidade de inserção e permanência no Ensino Superior. $O$ grande período de trabalho também pode estar relacionado à necessidade de que parte da renda dos estudantes seja destinada para pagamento de mensalidades em relação ao curso, o que talvez também esteja atrelada à escolha da modalidade que, além de oferecer horários flexíveis, oferece menores custos em relação às instituições privadas presenciais.

Figura 9 - Situação de trabalho dos respondentes. 


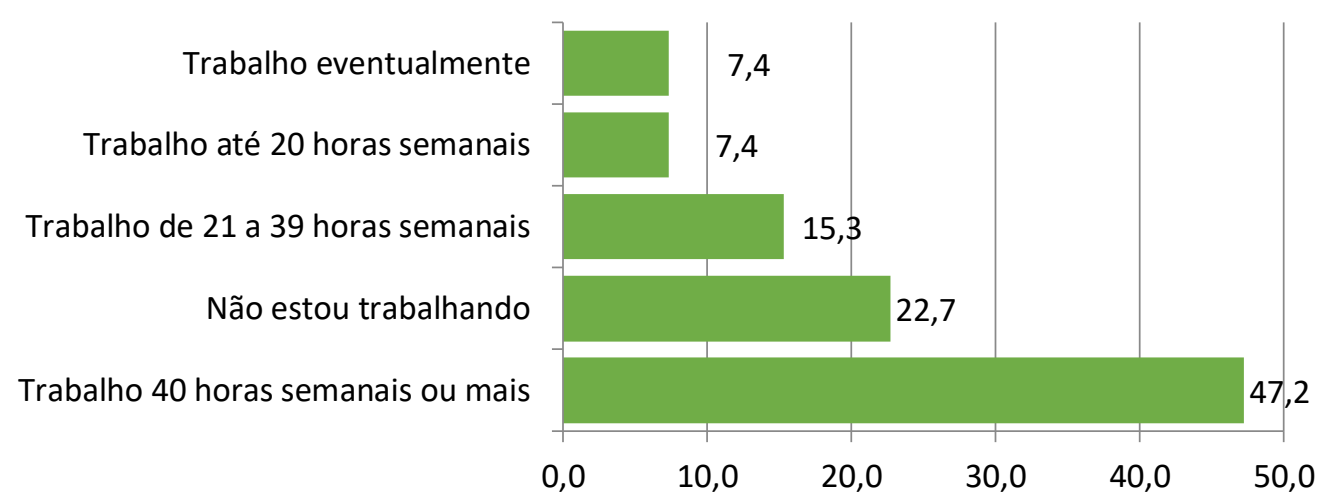

Fonte: Elaborada pelos autores com base na pesquisa realizada.

Ainda em relação à possibilidade de custos menores, existem também as condições de bolsas oferecidas pelo governo e pelas próprias instituições em parceria com o Estado. Como evidenciado no gráfico da Figura 10, a maior porcentagem de bolsas é oferecida pelas próprias instituições $(27,6 \%)$. A possibilidade de crescimento dessa categoria de bolsas pode estar relacionada à crise que vem assolando o Fundo do Financiamento Estudantil (FIES) desde 2015 (SEMESP, 2020). O gráfico demonstra que apenas $0,6 \%$ dos pesquisados são amparados pelo programa, e que $27,6 \%$ dos participantes não possuem nenhuma bolsa, o que de fato evidencia as possibilidades de acesso à EaD em relação aos seus menores custos e maiores oportunidades de financiamento.

Figura 10 - Situação dos respondentes quanto ao recebimento de bolsas e financiamentos

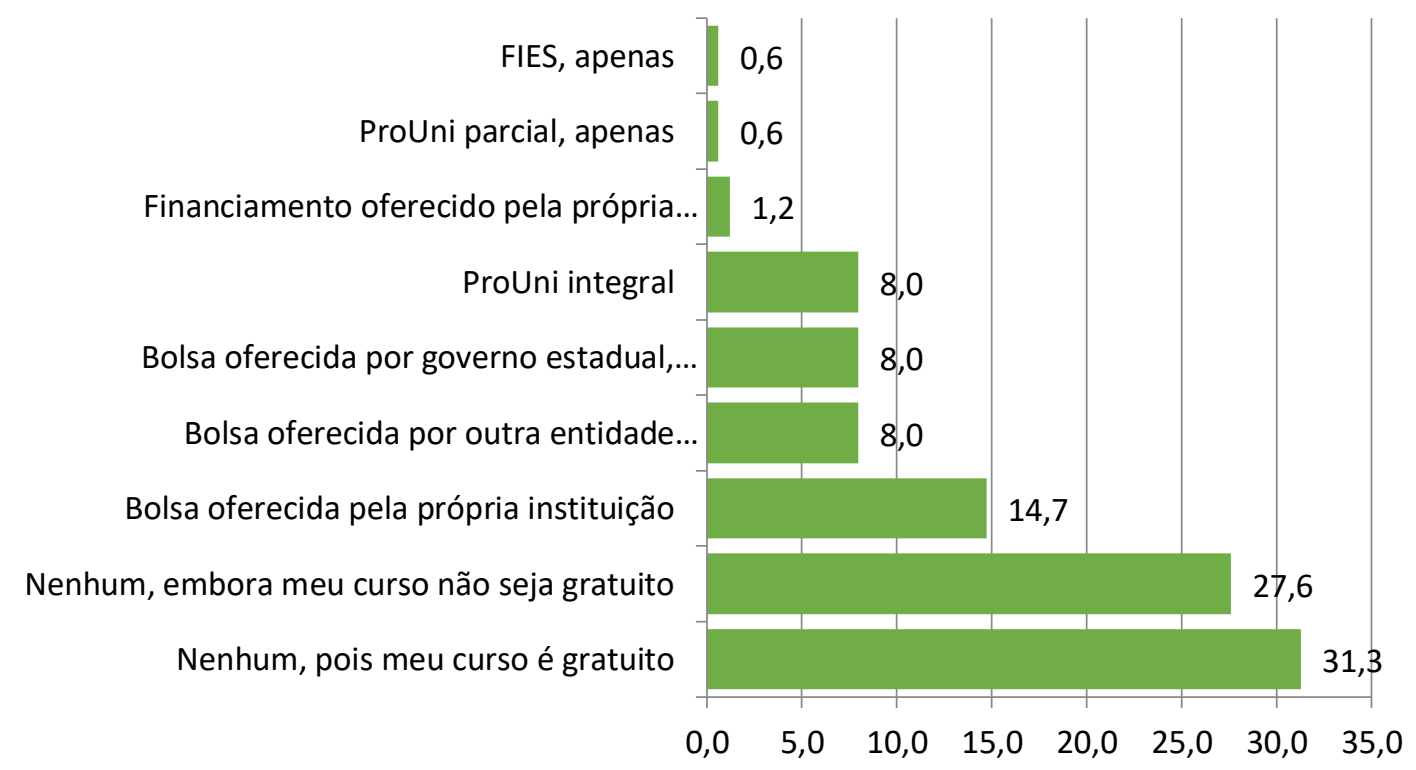

Fonte: Elaborada pelos autores com base na pesquisa realizada. 


\subsubsection{Aspectos contextuais do isolamento social: demandas domésticas e disponibilidade de recursos}

Ao perfil socioeconômico dos estudantes EaD, somam-se informações relativas às suas percepções das repercussões da pandemia sobre seu cotidiano familiar, suas demandas domésticas e a disponibilidade de recursos para as atividades acadêmicas.

A maior parte dos respondentes relatou que as pessoas do seu círculo doméstico guardaram medidas de isolamento social - Figura 11. Cerca de um quarto dos entrevistados, no entanto, apontaram que moradores de sua residência - incluindo eles próprios - mantiveram o distanciamento apenas parcialmente.

Figura 11 - Percentual de pessoas do círculo doméstico que mantiveram isolamento social no contexto da pandemia, 2020

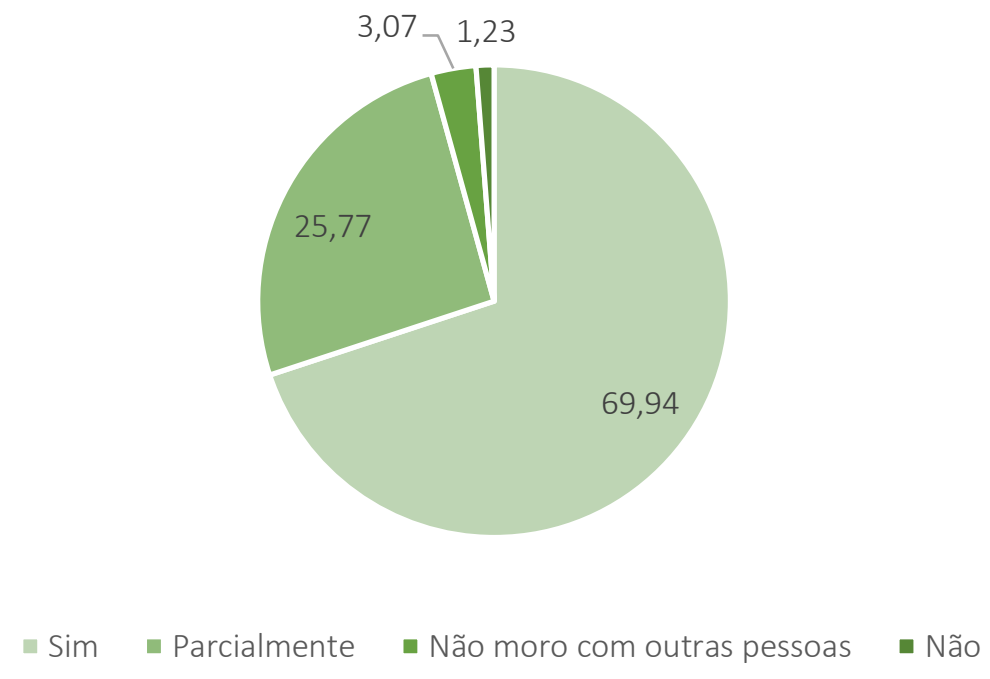

Fonte: Elaborada pelos autores com base na pesquisa realizada.

O número substancial de pessoas do círculo de convivência dos estudantes EaD que não fizeram isolamento social completo pode ser explicado, dentre outras causas, pelas dificuldades econômicas de se manterem afastados do trabalho ou por não terem a possibilidade de adotar regimes de home office. Dado que mais da metade desses estudantes pertencem às classes C e D, pode ser fator explicativo a necessidade da manutenção de atividades econômicas e de subsistência.

Por outro lado, como a maioria dos respondentes e seus familiares adotaram medidas de isolamento, e tendo em vista que, em geral, são mulheres jovens adultas, moradoras de capital, que residem com três ou mais pessoas, sem bolsa de estudo para financiar sua graduação e que precisam trabalhar 40 horas por semana, pode-se inferir que as políticas de isolamento social como forma de enfrentamento à pandemia fizeram com que seus estudos ocorressem no mesmo ambiente da convivência familiar e profissional. Em outras palavras, as atividades acadêmicas precisaram ser conciliadas com tarefas domésticas, dinâmicas afetivas familiares e atividades profissionais, sejam estas remotas ou não. 
Dessa maneira, apenas um em cada cinco respondentes reportou não ter tido nenhuma dificuldade doméstica no cenário do distanciamento social - Figura 12. A maior dificuldade encontrada naquele contexto foi em relação às demandas familiares, como fazer compras e pequenos reparos. Essa dificuldade pode estar ligada às preocupações com o ambiente externo e eventuais aglomerações, como feiras, padarias e supermercados; e receber pessoas estranhas à convivência do núcleo doméstico, tais como prestadores de serviços. Da mesma maneira, tarefas domésticas como a limpar a casa, cozinhar, lavar e passar roupas foi motivo de dificuldade para um número expressivo de respondentes. Isso pode ter sido ocasionado pelo aumento de pessoas no ambiente familiar, ampliando o tempo destinado a essas ações.

\section{Figura 12 - Dificuldades em atividades do dia a dia durante o distanciamento social no contexto da pandemia, $2020^{*}$}

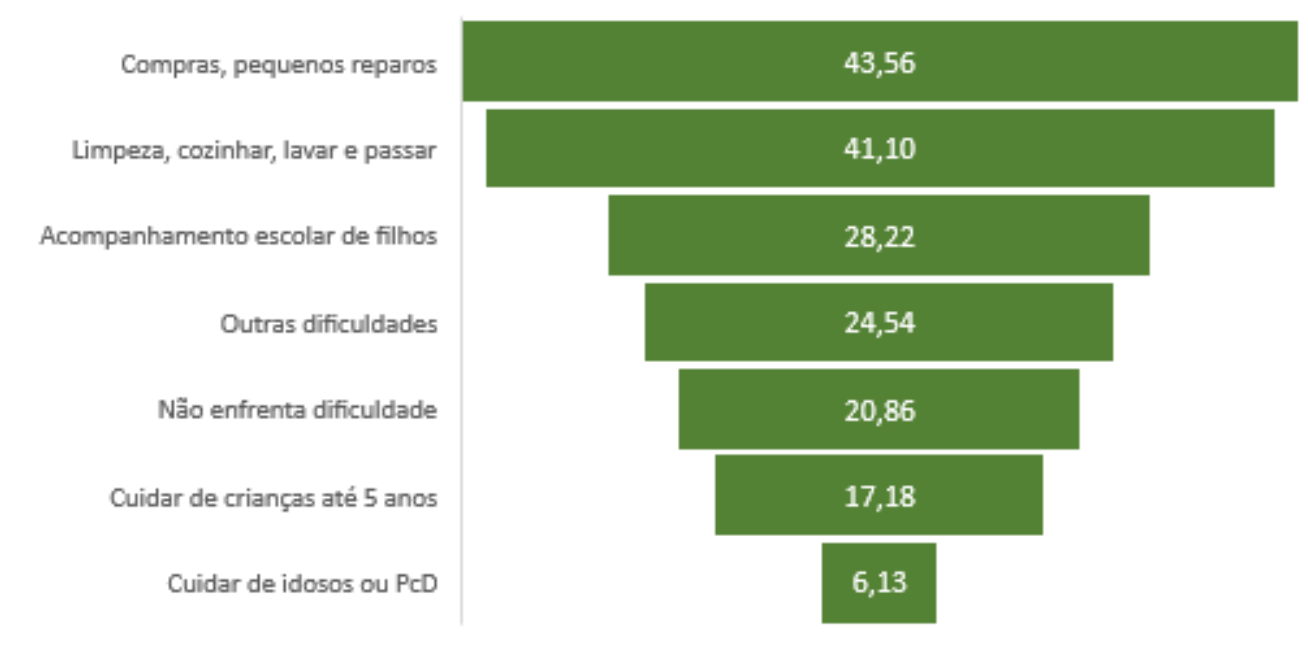

Fonte: Elaborada pelos autores com base na pesquisa realizada.

"A soma dos percentuais é maior que $100 \%$, pois os respondentes poderiam marcar mais de uma opção.

O gráfico da Figura 12 revela ainda que um número significativo de estudantes respondentes teve dificuldades durante o período de isolamento social em relação ao cuidado com filhos, sejam aqueles menores de 5 anos - mais dependentes dos pais na maioria dos aspectos afetivos, sociais, fisiológicos etc. -, seja no tocante ao acompanhamento escolar dos filhos com mais idade - nos Ensinos Fundamental e Médio.

Ajuda a explicar essas dificuldades a distribuição das tarefas entre os membros do círculo familiar - Figura 13. Foram, exatamente, as atividades domésticas que trouxeram maiores desafios aos respondentes no contexto da pandemia, pois são eles os responsáveis por exercêlas em sua maior parte. Os resultados mostraram que mais da metade dos estudantes da EaD lavam e passam roupas; cozinham sem auxílio de outros membros do círculo familiar. Tal fato explica, ainda que de forma parcial, a questão já levantada sobre o fato de a maioria dos estudantes EaD respondentes ser do sexo feminino - Figura 3 -, corroborando com a literatura que aponta que, mesmo atuando no mercado de trabalho formal - caso das participantes desta pesquisa, a maior parte delas cumpre jornadas de mais de 40 horas semanais - ainda são as mulheres as principais responsáveis pelas tarefas domésticas (BRITES, 2013; JESUS, 2018). 
Figura 13 - Distribuição das atividades domésticas durante o distanciamento social no contexto da pandemia, 2020

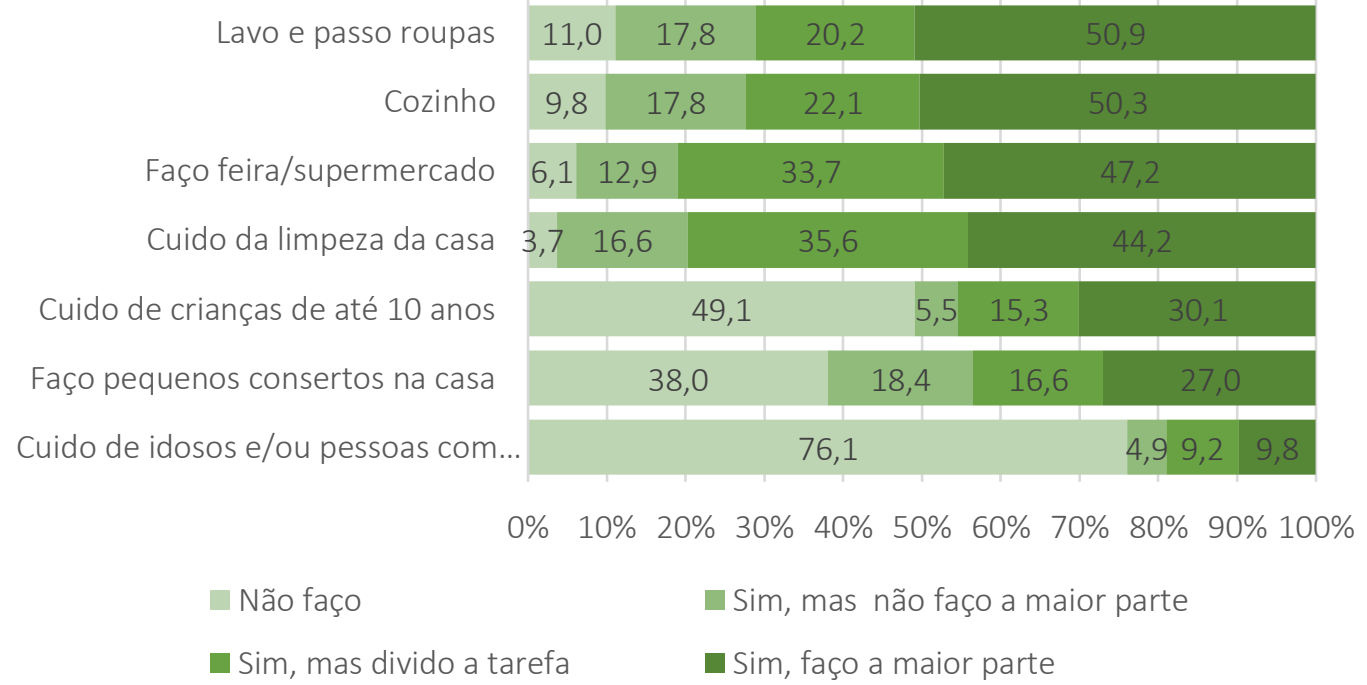

Fonte: Elaborada pelos autores com base na pesquisa realizada.

A não realização de tarefa somente foi expressiva quanto a pequenos consertos em casa e no cuidado de crianças de até 10 anos, idosos e pessoas com deficiência. A ausência em relação aos dois últimos pode ser explicada pela possível inexistência de sujeitos com essas características no círculo de convivência. A divisão de tarefas dos estudantes respondentes é mais significativa nas atividades de compras e limpeza da casa, o que contempla cerca de um terço dos participantes.

Em relação aos recursos tecnológicos e de internet disponíveis para os estudantes de graduação EaD, a pesquisa encontrou resultados contrários ao que a maior parte dos estudos sobre o ERE tem apontado (GESTRADO, 2020). Se os estudantes do ERE, em geral, acessam às aulas e atividades síncronas e assíncronas por meio de aparelhos de smartphones, os estudantes EaD, em sua maioria, utilizam os computadores de mesa e notebooks - $90 \%$ dos respondentes. Pode-se considerar que, por já estarem mais familiarizados com as dinâmicas do Ensino não presencial, esses estudantes já se organizam para cursar a graduação com recursos considerados mais adequados.

Apesar da maior parte dos estudantes respondentes reportarem que não precisaram compartilhar seus aparatos tecnológicos utilizados para estudos, um número significativo dividiu o dispositivo majoritariamente usado em suas atividades com um ou mais familiares durante o distanciamento social (Figura 14). O compartilhamento se deu mais com os filhos, seguido dos cônjuges; e $11 \%$ do total compartilharam seus dispositivos tanto com filhos quanto com cônjuges. 
Figura 14 - Compartilhamento de dispositivos durante o distanciamento social no contexto da pandemia, 2020*

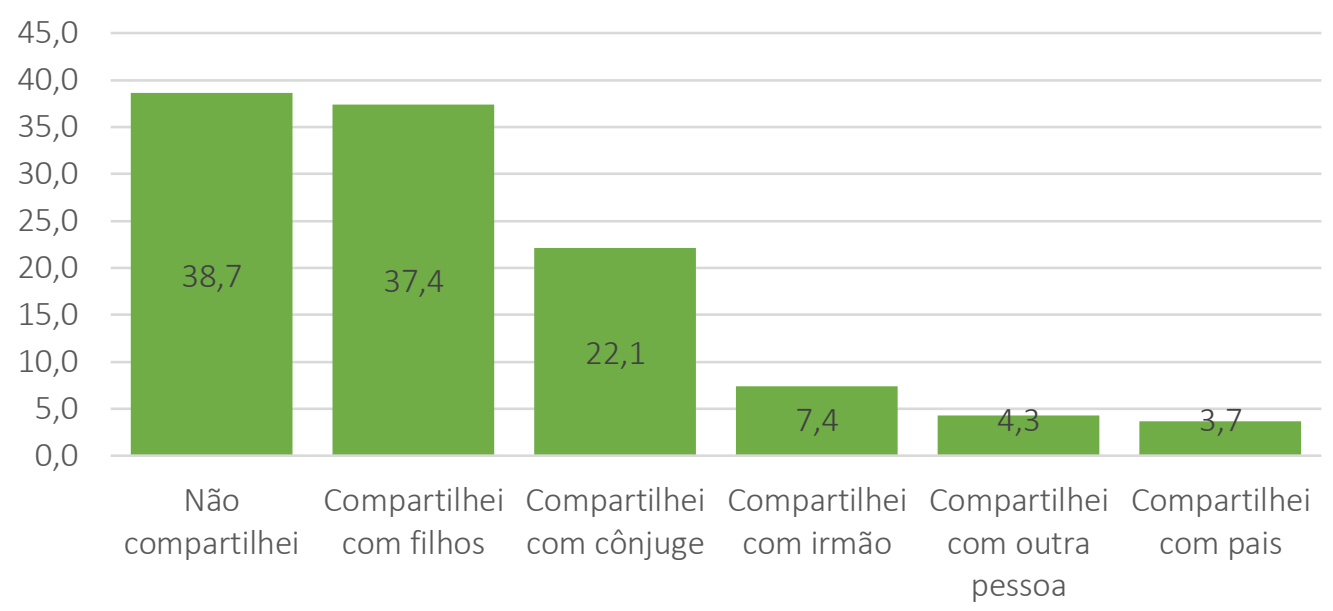

Fonte: Elaborada pelos autores com base na pesquisa realizada.

"A soma dos percentuais é superior a 100\%, pois os respondentes poderiam marcar mais de uma opção.

Dos estudantes que compartilharam o recurso, a maioria considerou que isso não afetou a rotina de estudos, enquanto $28,8 \%$ acreditaram que houve prejuízo. A despeito do questionário não permitir avaliar se o compartilhamento já ocorria antes do isolamento social, havia espaço para comentários sobre como a partilha do equipamento poderia ser prejudicial. Dentre os que responderam sobre o prejuízo da rotina, alguns comentários ajudam a elucidar as dificuldades advindas com o compartilhamento:

\footnotetext{
"Sempre tenho que fazer as atividades depois que minhas filhas dormem ou acabam as atividades delas".

"Sim, afetou negativamente os meus estudos, mas deu ao meu filho a oportunidade de acompanhar as aulas em casa. Portanto, em vários momentos eu deixei o meu estudo de lado para priorizar o estudo dele".

"No meu maior tempo disponível, que é a parte da manhã, enquanto meus filhos estão assistindo aula, não tenho o computador disponível para estudar". "Gastei o triplo ou mais do tempo de estudo usando outro aparelho digital inferior para estudar. Isso me causou muito estresse e desânimo".

"Tive que abrir mão das aulas online e optei por assistir gravações devido as aulas do cônjuge ser no mesmo horário".

"Eu e meus dois filhos estamos fazendo o curso superior em um notebook. Temos sempre que entrar em acordo e tomar cuidado para não marcar prova no mesmo horário. 0 curso deles é presencial só que com a pandemia passou a ser online assim como o meu".

"Antes da pandemia, eu possuía flexibilidade para escolher minhas horas de estudos pelo computador em comum acordo com minha irmã. Durante a pandemia minha rotina foi totalmente alterada, eu estudo basicamente quando há tempo disponível".

"Dependendo dos prazos de entrega de material, cada um tinha prioridade em usar computador".

"Sim, os horários que meus filhos estão com atividades de escola não posso usar o computador para minhas aulas, tive que me adequar com a mudança, ajudo eles com as atividades, cuido de casa, faço almoço, lavo roupas e depois tenho que estudar e fazer leitura minhas atividades escolares".
} 
Os dados da pesquisa apontam que o compartilhamento de rede de internet no contexto da pandemia afetou mais os estudantes EaD do que o compartilhamento dos dispositivos, conforme Figura 15. Menos de um terço dos respondentes não percebeu nenhuma diferença no acesso. Falhas e quedas de conexão; redução de velocidade; aumento de gastos em pacotes de dados foram críticas comuns sobre a internet no período.

Figura 15 - Mudanças na internet durante o distanciamento social no contexto da pandemia, 2020*

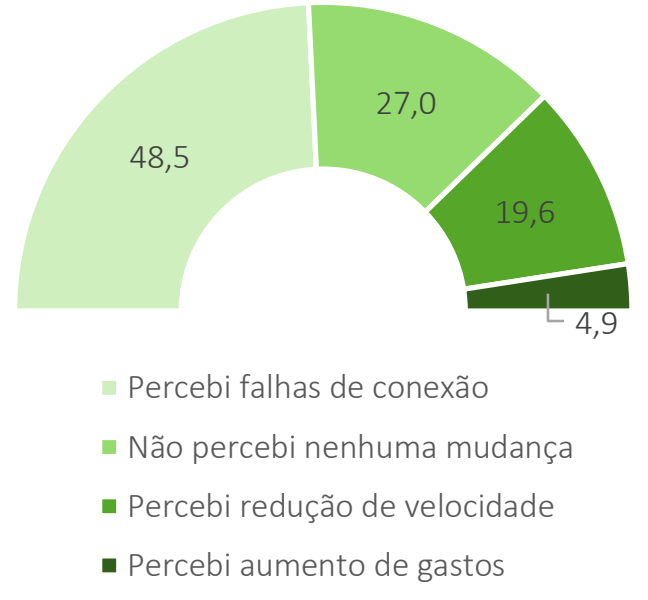

Fonte: Elaborada pelos autores com base na pesquisa realizada.

"A soma dos percentuais é superior a 100\%, pois os respondentes poderiam marcar mais de uma opção.

Dessa forma, os dados apresentados nesta seção, conjugados com os discutidos na seção precedente, dispõem que os estudantes de graduação EaD participantes desta pesquisa têm perfil socioeconômico correspondente ao verificado no Censo da Educação Superior do INEP (2018). Os dados demonstram também que o distanciamento social suscitado pela pandemia da COVID-19 em 2020 repercutiu em dificuldades na convivência familiar uma vez que parte considerável das atividades domésticas era realizada pelos próprios estudantes, com pouca divisão de tarefas, e que tais obrigações aumentaram no período pandêmico, segundo $51 \%$ dos respondentes.

Além disso, para um número significativo de estudantes, o contexto da pandemia demandou compartilhamento de dispositivos tecnológicos, o que, na percepção de parte deles, prejudicou suas atividades acadêmicas. Para um percentual expressivo dos participantes, o cenário de distanciamento social também incidiu em piora na qualidade do acesso à internet, com falhas de conexão e redução de velocidade.

\subsubsection{Repercussões da pandemia nas atividades acadêmicas}

Os respondentes do questionário desta pesquisa foram perguntados se, na percepção deles, o tempo despendido com responsabilidades domésticas e familiares ocasionadas pelas medidas de distanciamento social afetaram de alguma forma suas atividades acadêmicas. 0 resultado mostrou que $65,6 \%$ responderam que sim ao questionamento. 
Em relação ao número de horas dedicadas aos estudos, o gráfico da Figura 16 permite a visualização das mudanças em relação ao período anterior e posterior à pandemia e as medidas de isolamento social. As variações nas colunas de "De uma a três horas" e "De quatro a sete horas" podem sugerir uma substituição de uma pela outra, ou seja, estudantes que se dedicavam de quatro a sete horas semanais passaram a se dedicar de uma a três horas apenas.

Figura 16 - Número de horas dedicadas às atividades acadêmicas antes e durante o distanciamento social no contexto da pandemia, 2020

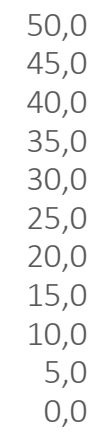

0,0

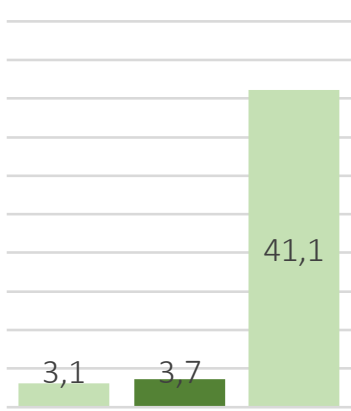

Nenhuma, apenas assistia

às aulas

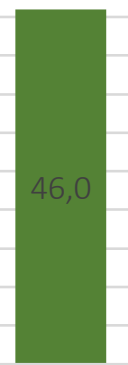

De uma a três

$$
\text { ês }
$$

16,0

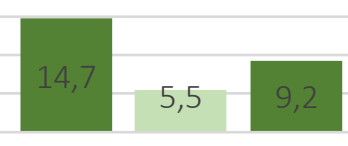

De oito a doze Mais de doze sete

Antes do isolamento Durante o isolamento

Fonte: Elaborada pelos autores com base na pesquisa realizada.

É possível destacar também que houve variação nos extremos: o número de estudantes que apenas assistia às aulas teve ligeiro acréscimo; e o percentual de respondentes que estudavam acima de doze horas semanais ampliou. Destes, $40 \%$ estudavam de oito a doze horas semanais antes da pandemia, aumentando seu tempo de dedicação no contexto de distanciamento social.

O gráfico da Figura 17 foi construído por meio de escala Likert, com cinco gradações de concordância para dez afirmativas. A afirmativa 1 - Por ser estudante de Educação a Distância, minha rotina não se alterou durante a pandemia - teve algum grau de discordância de mais da metade dos respondentes. Dessa forma, foi possível constatar que, ainda que a maior parte dos estudantes de graduação EaD tenham tido sua rotina alterada, um em cada três respondentes não percebeu grandes alterações em suas atividades acadêmicas.

Sobre a percepção de resultados educacionais, a afirmativa 2 - Meu rendimento acadêmico piorou no período da pandemia -, apesar da percepção majoritária de alteração da rotina, os respondentes, em geral, não concordam que isso piorou estritamente o rendimento. Da mesmo modo, também discordam de que houve uma alteração na atuação por parte de seus professores - afirmativa 3. No entanto, para 31,3\% dos estudantes, o rendimento acadêmico sofreu uma piora; e para um quarto do total de respondentes, a pandemia afetou também a atuação de seus professores. 
Figura 17 - Percepção sobre as repercussões do distanciamento social nas relações de ensinoaprendizagem no contexto da pandemia, 2020

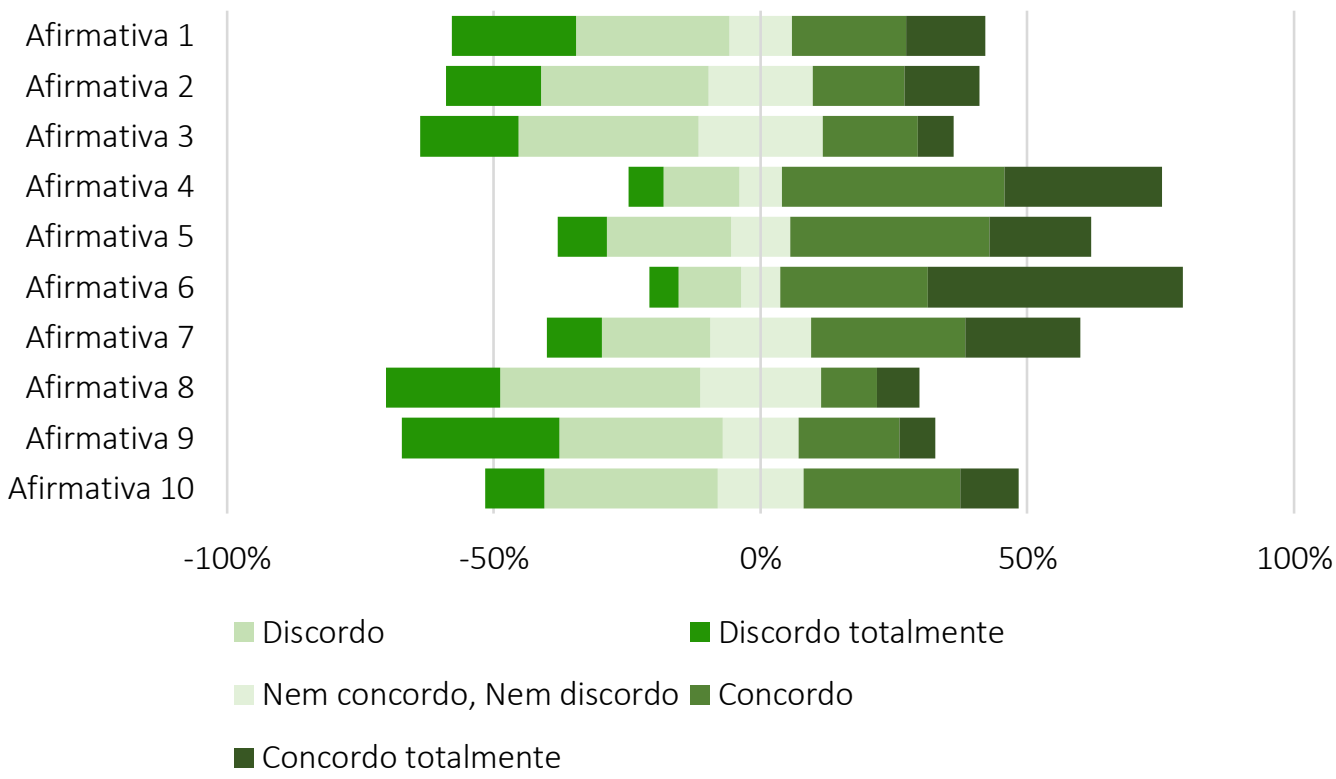

Fonte: Elaborada pelos autores, com base na pesquisa realizada.

A maioria dos estudantes $\operatorname{EaD}(71,1 \%)$ concorda com a afirmativa 4, de que seus aparelhos tecnológicos de uso nas aulas e atividades on-line foram suficientes no período da pandemia. Da mesma forma, mais da metade deles (56,4\%) julgou que a afirmativa 5 - Meu serviço de internet foi suficiente para as demandas de aulas e atividades on-line no período - é verdadeira.

De todas as afirmativas, a que apresentou maior percentual de convergência de respostas foi a 6 - Me senti mais cansado do que o habitual no contexto da pandemia -, que teve concordância de 3 em cada 4 respondentes. Esse cansaço pode ser explicado em parte pelo aumento de tarefas domésticas, conforme afirmativa 7 - Minhas tarefas familiares no período da pandemia me atrapalharam quanto às minhas rotinas acadêmicas -, em que metade dos estudantes respondentes estiveram de acordo.

A partir das respostas, também é possível inferir que as instituições de Ensino Superior ofereceram algum tipo de suporte no período da pandemia, mesmo para os graduandos da modalidade EaD, pois 58,9\% dos estudantes discordaram da afirmativa 8 - Por ser estudante da Educação a Distância, não recebi nenhum tipo de auxílio ou apoio por parte da minha IES -, apontando que receberam apoio no contexto do distanciamento social.

Houve um número expressivo de discordância em relação à afirmativa 9 - Minha saúde mental não foi afetada no período da pandemia -, o que se somou à percepção de cansaço no decorrer de 2020, ou seja, o cenário da pandemia, em suas diversas dimensões, afetou os sujeitos de múltiplas maneiras.

Por fim, a última afirmativa sobre o comprometimento da aprendizagem do estudante da EaD no período de distanciamento social foi a que apresentou maior heterogeneidade de respostas, sendo juntamente com a afirmativa 2 as únicas que não alcançaram mais de $50 \%$ de concordância ou discordância. Para a afirmativa 10,43,5\% dos estudantes tiveram algum grau de discordância, e 40,4\% algum grau de concordância. Uma possível explicação é que as medidas de 
isolamento social afetaram de maneira muito desigual os diferentes sujeitos. Estudantes já acostumados a um modelo não presencial de ensino-aprendizagem, ao se depararem com um cenário adverso, reagiram de formas distintas, ocasionando percepções e apropriações da realidade dissonantes.

\section{CONSIDERAÇÕES FINAIS}

A pandemia da COVID-19 incidiu de maneira substancial em todas as dimensões da vida econômica e social no Brasil e no mundo. A interrupção de serviços, bem como o fechamento de estabelecimentos, medidas de isolamento social e quarentena modificaram comportamentos tanto na esfera pública quanto na privada. No caso da educação, milhões de crianças, jovens e adultos tiveram suas rotinas escolares afetadas, seja devido à suspensão das atividades acadêmicas, seja pela adoção de estratégias de Ensino Remoto Emergencial.

Por um lado, as instituições de Ensino Superior que ofertavam cursos de graduação na modalidade EaD puderam dar continuidade as suas atividades, uma vez que seus alunos já estavam em regime não presencial de estudos. Em outro aspecto, porém, esses estudantes, por estarem inseridos no mercado de trabalho e por suas dinâmicas familiares e de sociabilidade, também estavam sujeitos a enfrentarem obstáculos e dificuldades advindos com a emergência em saúde pública.

Esta pesquisa, ao investigar como a pandemia impactou os processos de ensinoaprendizagem de estudantes regularmente matriculados em cursos de graduação EaD, levantou informações que podem contribuir com as reflexões acerca do cenário de distanciamento social sobre os estudantes dessa modalidade. Os dados apontaram que, em geral, o aluno da EaD no Brasil é mulher, jovem adulta, que é casada e tem filhos, não recebe bolsa ou financiamento, precisando trabalhar para custear seus próprios estudos e contribuir no orçamento doméstico. Dessa forma, ainda que a pandemia não tenha suscitado suspensão ou modificação direta de suas atividades acadêmicas, seu contexto doméstico, familiar e profissional foi impactado, o que se refletiu em seus estudos.

Apesar de já disporem de equipamentos e internet adequados para aulas e atividades síncronas e assíncronas, a presença constante de pessoas em suas casas em dias e horários que não estariam, gerou, para parte dos estudantes, ampliação das tarefas domésticas; compartilhamento de espaços e dispositivos tecnológicos; redução da qualidade e velocidade da conexão; diminuição do tempo destinado aos estudos; aumento do cansaço físico e mental.

Essas repercussões contextuais, no entanto, desdobraram-se em percepções distintas sobre os impactos da pandemia, isto é, as medidas de isolamento social afetaram desigualmente os estudantes EaD, em que parte deles não considerou que houve alterações significativas em seu rendimento acadêmico. Por outro lado, para um percentual expressivo, a qualidade de sua aprendizagem se reduziu no período.

Conclui-se, assim, que ao contrário do que se poderia intuitivamente imaginar, a pandemia da COVID-19 e as políticas de isolamento social também impactaram as relações de ensinoaprendizagem de estudantes EaD. Há indícios, no entanto, de que esse impacto possa ter sido menor do que para os estudantes de regime presencial de instituições que adotaram o ERE. 
Constitui-se como limitações deste trabalho o fato de não terem sido avaliadas as repercussões da pandemia para estudantes EaD de forma desagregada. Dessa maneira, sugerese para trabalhos futuros a análise de como as relações de ensino-aprendizagem de estudantes de diferentes gêneros, idades, regiões do país e nível socioeconômico reagiram ao contexto da pandemia. Espera-se que esta pesquisa contribua ao campo de estudos da Educação a Distância, fornecendo elementos para a reflexão tanto no aspecto específico dos impactos da pandemia quanto de maneira geral, a fim de se aprimorar na teoria, na prática e no tocante às políticas públicas, essa modalidade.

\section{REFERÊNCIAS}

ASSOCIAÇÃO BRASILEIRA DE ENSINO A DISTÂNCIA (ABED). Censo EAD.BR: relatório analítico da aprendizagem a distância no Brasil 2016. Curitiba: InterSaberes, 2017. Disponível em: http://abed.org.br/censoead2016/Censo_EAD_2016_portugues.pdf. Acesso em: 09 dez. 2020.

ABREU, B. M. Inclusão e acessibilidade em tempos de pandemia. Pedagogia em Ação, Belo Horizonte, v. 13, n. 1, 2020. Disponível em: http://periodicos.pucminas.br/index.php/pedagogiacao/article/view/23705. Acesso em: 22 jan. 2021.

ALONSO, K. M.; SILVA, D. G. A educação a distância e a formação on-line: o cenário das pesquisas, metodologias e tendências. Educação e Sociedade, Campinas, v. 39, n. 143, p. 499-514, jun. 2018. Disponível em: https://doi.org/10.1590/es0101-73302018200082. Acesso em: 9 dez. 2020.

ASSOCIAÇÃO NACIONAL DE DIRIGENTES DAS INSTITUIÇÕES FEDERAIS DE ENSINO SUPERIOR (ANDIFES). $\mathbf{V}$ Pesquisa Nacional de Perfil Socioeconômico e Cultural dos (as) Graduandos (as) das IFES - 2018. Brasília, DF: ANDIFES, 2019. Disponível em: https://www.andifes.org.br/wp-content/uploads/2019/05/VPesquisa-Nacional-de-Perfil-Socioeconomico-e-Cultural-dos-as-Graduandos-as-das-IFES-2018.pdf. Acesso em: 9 dez. 2020.

ARRUDA, E. P.; ARRUDA, D. E. P. Educação à Distância no Brasil: Políticas Públicas e Democratização do Acesso ao Ensino Superior. Educação em Revista, Belo Horizonte, v. 31, n. 3, p. 321-338, set. 2015. Disponível em: http://dx.doi.org/10.1590/0102-4698117010. Acesso em: 09 dez. 2020.

ARRUDA, E. P. Educação Remota Emergencial: elementos para políticas públicas na educação brasileira em tempos de Covid-19. EmRede: Revista de Educação a Distância, Porto Alegre, v. 7, n. 1, p. 257-275, mai. 2020. Disponível em: https://www.aunirede.org.br/revista/index.php/emrede/article/view/621. Acesso em: 12 dez. 2020.

BRASIL. Decreto $n^{\circ} 10.282$, de 20 de março de 2020. Regulamenta a Lei $n^{\circ} 13.979$, de 6 de fevereiro de 2020, para definir os serviços públicos e as atividades essenciais. Diário Oficial da União: seção 1, Brasília, DF, p. 1, 20 mar. 2020. Disponível em: http://www.planalto.gov.br/ccivil_03/_ato20192022/2020/decreto/D10282.htm. Acesso em: 17 nov. 2020.

BRASIL. Decreto $n^{\circ} 2.494$, de 10 de fevereiro de 1998. Regulamenta o art. 80 da Lei $n^{\circ} 9.394$, de 20 de dezembro de 1996, e dá outras providências. Diário Oficial da União: seção 1, Brasília, DF, p. 1, 11 fev. 1998. Disponível em: https://www2.camara.leg.br/legin/fed/decret/1998/decreto-2494-10-fevereiro-1998397980-publicacaooriginal-1-pe.html. Acesso em: 20 dez. 2020

BRASIL. Decreto $n^{\circ}$ 5.622, de 19 de dezembro de 2005. Regulamenta o Art. 80 da Lei $n^{\circ}$ 9.394, de 20 de dezembro de 1996, que estabelece as diretrizes e bases da educação nacional. Diário Oficial da União: 
seção 1, Brasília, DF, p. 1, 20 dez. 2005. Disponível em: http://www.planalto.gov.br/ccivil_03/_ato20042006/2005/decreto/d5622.htm. Acesso em: 20 dez. 2020.

BRASIL. Decreto $n^{\circ}$ 9.057, de 25 de maio de 2017. Regulamenta o Art. 80 da Lei $n^{\circ} 9.394$, de 20 de dezembro de 1996, que estabelece as diretrizes e bases da educação nacional. Diário Oficial da União: seção 1, Brasília, DF, n. 100, p. 3, 26 mai. 2017. Disponível em: https://www.in.gov.br/materia//asset_publisher/Kujrw0TZC2Mb/content/id/20238603/do1-2017-05-26-decreto-n-9-057-de-25-de-maiode-2017-20238503. Acesso em: 20 dez. 2020.

BRASIL. Lei n 9.394, de 20 de dezembro de 1996. Lei das Diretrizes e Bases da Educação Nacional. Estabelece as diretrizes e bases da educação nacional. Diário Oficial da União: seção 1, Brasília, DF, p. 27933, 23 dez. 1996. Disponível em: http://www.planalto.gov.br/ccivil_03/LEIS/I9394.htm. Acesso em: 20 dez. 2020.

BRITES, J. G. Trabalho doméstico: questões, leituras e políticas. Cadernos de Pesquisa, São Paulo, v. 43, n. 149, p. 422-451, ago. 2013. Disponível em: https://doi.org/10.1590/S0100-15742013000200004. Acesso em: 22 jan. 2021.

CURY, C. R. J. Educação escolar e pandemia. Pedagogia em Ação, Belo Horizonte, v. 13, n. 1, p. 8-16, 2020. Disponível em: http://periodicos.pucminas.br/index.php/pedagogiacao/article/view/23749. Acesso em: 17 nov. 2020.

DI BENEDITTO, A. P. M. A educação básica durante o distanciamento social: o legado de 2020. Brazilian Journal of Development, Curitiba, v. 6, n. 10, p. 82270-82282, out. 2020. Disponível em: https://doi.org/10.34117/bjdv6n10-599. Acesso em: 17 nov. 2020.

DIAS, E.; PINTO, F. C. F. A educação e a Covid-19. Ensaio: avaliação e políticas públicas em educação, Rio de Janeiro, v. 28, n. 108, p. 545-554, jul./set. 2020. Disponível em: https://doi.org/10.1590/s010440362019002801080001 . Acesso em: 17 nov. 2020.

DUTRA; J. L. C.; CARVALHO, N. C. C.; SARAIVA, T. A. R. Os efeitos da pandemia de Covid-19 na saúde mental das crianças. Pedagogia em Ação, Belo Horizonte, v.13, n. 1, p. 293-301, 2020. Disponível em: http://periodicos.pucminas.br/index.php/pedagogiacao/article/view/23772. Acesso em: 17 nov. 2020.

GARRIDO, F. A. Z. Docência universitária durante a pandemia da COVID-19: um olhar do Chile. Revista Docência do Ensino Superior, Belo Horizonte, v. 10, 2020. Disponível em: https://doi.org/10.35699/22375864.2020.24777. Acesso em: 17 nov. 2020.

GRUPO DE ESTUDOS SOBRE POLITIICA EDUCACIONAL E TRABALHO DOCENTE (GESTRADO). Trabalho Docente em Tempos de Pandemia: Relatório Técnico. Belo Horizonte: CNTE, 2020. Disponível em: https://www.cnte.org.br/images/stories/2020/cnte_relatorio_da_pesquisa_covid_gestrado_julho2020.pd f. Acesso em: 22 set. 2020.

HODGES, C. et al. The difference between emergency remote teaching and online learning. EDUCAUSE Review, 27 mar. 2020. Disponível em: https://er.educause.edu/articles/2020/3/the-difference-betweenemergency-remote-teaching-and-online-learning. Acesso em: 21 ago. 2020.

INSTITUTO NACIONAL DE ESTUDOS E PESQUISAS EDUCACIONAIS ANÍSIO TEIXEIRA (INEP). Censo da Educação Superior: Microdados do Censo da Educação Superior. 2018. Disponível em: https://www.gov.br/inep/pt-br/acesso-a-informacao/dados-abertos/microdados/censo-da-educacaosuperior. Acesso em: 06 out. 2020.

INSTITUTO NACIONAL DE ESTUDOS E PESQUISAS EDUCACIONAIS ANÍSIO TEIXEIRA (INEP). Enade: Microdados do Exame Nacional de Desempenho dos Estudantes. 2017-2019. Disponível em: 
https://www.gov.br/inep/pt-br/acesso-a-informacao/dados-abertos/microdados/enade. Acesso em: 06 out. 2020. era 2018

JESUS, J. C. Trabalho doméstico não remunerado no Brasil: uma análise de produção, consumo e transferência. 2018. Tese (Doutorado em Demografia) - Faculdade de Ciências Econômicas, Universidade Federal de Minas Gerais, Belo Horizonte, 2018. Disponível em:

https://repositorio.ufmg.br/bitstream/1843/FACE-

B27PW9/1/ppgdemografia_jordanacristinajesus_tesedoutorado.pdf. Acesso em: 21 ago. 2020.

MAIA, B. R.; DIAS, P. C. Ansiedade, depressão e estresse em estudantes universitários: o impacto da COVID19. Estudos de Psicologia, Campinas, v. 37, 2020. Disponível em:

https://www.scielo.br/j/estpsi/a/k9KTBz398jqfvDLby3QjTHJ/?lang=pt. Acesso em: 6 jan. 2021.

OLIVEIRA, D. A. Condições de trabalho docente e a defesa da escola pública: fragilidades evidenciadas pela pandemia. Revista USP, São Paulo, n. 127, p. 27-40, 2021. Disponível em: https://www.revistas.usp.br/revusp/article/view/180037. Acesso em: 6 jan. 2021.

OLIVEIRA, G.; MOTA, J. Q.; BRAGA, D. S. Desafios em tempos de pandemia: reflexões da professora Gabrielle Oliveira sobre educação e desigualdades. Revista Docência do Ensino Superior, Belo Horizonte, v. 10, 2020. Disponível em: https://periodicos.ufmg.br/index.php/rdes/article/view/25682. Acesso em: 17 nov. 2020.

WORLD HEALTH ORGANIZATION (WHO). WHO Coronavirus Disease (COVID-19) Dashboard. 2020a. Disponível em: https://covid19.who.int/. Acesso em: 17 nov. 2020.

WORLD HEALTH ORGANIZATION (WHO). "Immunity passports" in the context of COVID-19: Scientific brief. 2020b. Disponível em: https://www.who.int/news-room/commentaries/detail/immunity-passportsin-the-context-of-covid-19. Acesso em: 17 nov. 2020.

ORGANIZAÇÃO PAN-AMERICANA DE SAÚDE (OPAS). Considerações sobre medidas de distanciamento social no contexto da resposta à pandemia de Covid-19. 2020. Disponível em: https://www.paho.org/bra/index.php?option=com_docman\&view=download\&alias=1990-apresentacaoconsideracoes-distanciamento-social\&category_slug=covid-19-materiais-de-comunicacao-1\&ltemid=965. Acesso em: 17 nov. 2020.

PALÚ, J.; SCHÜTZ, J. A.; MAYER, L. (Org.). Desafios da educação em tempos de pandemia. Cruz Alta: Ilustração, 2020.

PARIZOT, I. A pesquisa por questionário. In: POUPART, J. et al. A pesquisa qualitativa. Petrópolis: Vozes, 2008.

PEREIRA, M. S. et al. Núcleo Docente Estruturante da Enfermagem da UFMG: da criação aos tempos da pandemia da Covid-19. Revista Docência do Ensino Superior, Belo Horizonte, v. 10, p. 1-19, 2020. Disponível em: https://doi.org/10.35699/2237-5864.2020.23903. Acesso em: 17 nov. 2020.

PINHEIRO, J. I. D. et al. Probabilidade e Estatística. São Paulo: Campus, 2012.

RIBEIRO, M. P.; CLÍMACO, F. C. Impactos da pandemia na educação infantil: a pandemia acelerou a necessidade de se problematizar a questão digital na educação infantil?. Pedagogia em Ação, Belo Horizonte, v. 13, n. 1, p. 96-110, 2020. Disponível em:

http://periodicos.pucminas.br/index.php/pedagogiacao/article/view/23756. Acesso em: 17 nov. 2020. 
SINDICATO DAS ENTIDADES MANTENEDORAS DE ESTABELECIMENTOS DE ENSINO SUPERIOR (SEMESP).

Mapa de Ensino Superior no Brasil. 10. ed. São Paulo: Instituto Semesp, 2020.

https://www.semesp.org.br/mapa-do-ensino-superior/edicao-10. Acesso em: 10 de dez. 2020.

ORGANIZAÇÃO DAS NAÇÕES UNIDAS PARA A EDUCAÇÃO, A CIÊNCIA E A CULTURA (UNESCO). Educação: da interrupção à recuperação. 2020. Disponível em: https://pt.unesco.org/covid19/educationresponse.

Acesso em: 17 nov. 2020.

\footnotetext{
i Posteriormente, a Portaria recebeu ajustes e acréscimos por meio das Portarias no 345, de 19 de março de 2020 e no 356, de 20 de março de 2020. Outras legislações sobre o tema forma o Parecer CNE/CP no 5/2020, de 28 de abril de 2020; a Lei no 14.040, de 18 de agosto de 2020; o Parecer CNE/CP n 11, de 7 de julho de 2020 e o Parecer CNE/CP no 16/2020, de 9 de outubro de 2020.

ii Até a conclusão deste texto, tanto a Revista EmRede quanto a EaD em Foco estavam com submissões abertas para dossiês temáticos sobre o ensino no contexto da pandemia de COVID-19.

iii Apesar de tratar de pesquisa envolvendo seres humanos, o questionário não foi submetido em comitê de ética pelo disposto no inciso I do parágrafo único do artigo $1^{\circ}$ da Resolução no 510, de 7 de abril de 2016 do Conselho Nacional de Saúde.
} 